\title{
SOBRE UM ESCRAVO QUE SABIA LER E O PRINCÍPIO DE UMA SUPOSTA INSURREIÇÃO EM CAMPOS DOS GOYTACAZES (1871-1877)
}

\author{
ABOUT A SLAVE WHO COULD READ \\ AND THE BEGGININGS OF A SUPPOSED INSURRECTION \\ IN CAMPOS DOS GOYTACAZES (1871-1877)
}

\author{
Carlos Eugênio Soares de Lemos \\ Rafaela Machado Ribeiro*
}

\begin{abstract}
RESUMO: O presente artigo discute uma acusação de insurreição liderada por um escravo que sabia ler, na cidade de Campos dos Goytacazes, província do Rio de Janeiro, no período de crise do escravismo. Partindo de uma abordagem que concebe os sujeitos sociais como agentes, baseado em fontes como auto de perguntas, jornais, relatórios e inventários, tem por objetivo investigar de que modo a inscrição desses escravos em outras posições discursivas, que não as de submissão à lógica da classe senhorial, levou-os a se apropriarem de um enunciado liberal para se rebelarem contra a ordem escravocrata. Ao final, concluímos que a correspondência entre as transformações socioeconômicas em curso e a reflexão dos escravos sobre o que era aceitável ou não em sua condição concorreu para uma redefinição de sua posição na relação com os seus senhores.
\end{abstract}

PALAVRAS-CHAVE: Crise do escravismo. Insurreição. Discursos.

ABSTRACT: This article discusses an accusation of insurrection led by a literate slave, in the city of Campos dos Goytacazes, province of Rio de Janeiro, during the period of the slavery crisis. In a conception of social subjects as agents-based approach, based on sources such as police questionings, journals, reports and inventories, the objective is to investigate how the inscription of these slaves in other discursive positions rather than those of submission to the logic of class, led them to appropriate a liberal statement to rebel against the slave-owning order. In the end, we conclude that the relationship between ongoing socioeconomic transformations and the reflection of slaves on what was acceptable or not in their condition contributed to the redefinition of their position in the relationship with their masters.

KEYWORDS: Crisis of slavery. Insurrection. Speeches.

\section{Introdução}

Que tinha combinado com seos companheiros de, reunidos irem entenderse com seo senhor e declarar-Ihe que não querião mais trabalhar e que se seo senhor insistisse em que elles voltassem para o trabalho sem Ihes pagar os seos jornáes que irião para a Cidade queixar-se à Justiça. Que das sete para as oito horas da noute reunirão-se na coxeira para

\footnotetext{
* Professor do Departamento de Ciências Sociais da Universidade Federal Fluminense, Pólo Universitário de Campos dos Goytacazes (PUCG/UFF). Doutor em Ciências Humanas (Sociologia) pela Universidade Federal do Rio de Janeiro (2007). Atua nas áreas de História Regional e Análise do Discurso.

** Doutoranda em História Política e Social pela Universidade Federal do Espírito Santo, Mestre em Sociologia Política pela Universidade Estadual do Norte Fluminense, Graduada em História pelo Centro Universitário Fluminense (UNIFLU). Pesquisadora do Arquivo Público Municipal Waldir de Carvalho, Campos dos GoytacazesRJ.
} 
deliberarem e ali assentarão de fazerem isso quando fosse chamados para a revista da manhã. Que já tinhão esse trato feito há mais de um mez, e que tinha lido no Monitor por onde se convencia que érão livres, e que o trabalho livre devia ser pago. ${ }^{60}$

No dia 09 de maio de 1877, o escravo Manoel "Çacramento" foi conduzido à delegacia sob acusação de ser o mentor de uma suposta rebelião que aconteceria na fazenda Engenho do Queimado, pertencente ao comendador Julião Ribeiro de Castro. Esse proprietário de terras e escravos, filho do falecido barão de Santa Rita (1767-1854), era um homem de idade avançada, 70 anos, que dividia a administração de seus negócios com 0 seu filho de 32 anos, o major da Guarda Nacional, José Julião Ribeiro de Castro. Ambos gozavam de prestígio político no Partido Conservador local e de boa reputação na imprensa, sendo figuras estimadas na Ordem $3^{\underline{a}}$ de N. S ${ }^{\underline{a}}$ do Monte do Carmo, e o seu clã familiar era uma referência para a boa sociedade do rico e populoso município de Campos dos Goytacazes.

No auto de perguntas, conduzido pelo delegado, o escravo Manoel "Çacramento" e os outros cinco que o acompanharam - Marcos, Matheus, Marcollino, Cezário e Apollinario foram interrogados sobre quem era o cabeça do movimento e quais os motivos que os levaram a tramar uma insurreição na fazenda do Queimado, considerada um modelo para as demais da região. Dentre as razões apresentadas, como a de serem "o serviço muito e o alimento insuficiente", "repetidos os castigos" e "poucas horas para repouzo", ${ }^{61}$ uma se destacava pelo seu teor, no mínimo, incomum: a leitura e interpretação de um enunciado sobre o trabalho livre num periódico local. Ao ler o Monitor Campista para os seus companheiros, folha que comprara com ajuda dos demais, Manoel "Çacramento" chegara à conclusão de que os seus braços eram livres e, como livres, o seu trabalho deveria receber jornal. E, nesse sentido, caso o seu senhor não quisesse atendê-los, que lhes desse a liberdade; do contrário, eles poderiam dar queixa à Justiça.

A crise do escravismo nas décadas finais do Império é o pano de fundo em que se desenrola esse episódio da fazenda do Queimado. Assim, analisamos como a inscrição dos escravos em outras posições discursivas, que não as de submissão à lógica da classe senhorial, levou-os a se apropriarem de um enunciado sobre o trabalho livre veiculado por um jornal liberal, transformando-o num argumento de autoridade para contestarem os abusos de seus senhores e reivindicarem a sua alforria. A partir de um conjunto de fontes textuais, como auto de perguntas, jornais, relatórios e inventários, baseados numa abordagem que considera o escravo como sujeito histórico e auxiliados pela análise materialista do discurso, problematizamos as disputas de sentido sobre o significado da suposta "insurreição" entre esses escravos do Engenho do Queimado e a classe senhorial da boa sociedade da freguesia de São Salvador, na cidade de Campos dos Goytacazes, na província do Rio de Janeiro.

\section{Historiografia, análise do discurso e documentos}

Com base no caminho aberto pela história social da escravidão nas décadas finais do século passado (CHALHOUB, 1990; REIS, 1993; CASTRO,1998), o caso de Manoel "Çacramento" nos oferece uma série de indicativos/enunciados sobre certas características das relações escravistas, na segunda metade dos oitocentos, que relativizam algumas ideias consagradas pela historiografia clássica do tema (FREIRE, 2004; GORENDER, 1978; CARDOSO, 1977). Assim, a natureza não violenta da nossa escravidão e as abordagens em que o escravo é apresentado como passivo ou rebelde, reificado ou heroico, dão lugar a

\footnotetext{
60 Auto de perguntas feitas aos escravos do Comendador Julião Ribeiro de Castro. Delegacia de Polícia do Termo de Campos, 09 de maio de 1877, pag. 02. In: Arquivo Público Municipal Waldir Pinto de Carvalho, Campos dos Goytacazes, Rio de Janeiro. Obs: Mantivemos os registros ortográficos e a sintaxe dos textos conforme se apresentaram nos documentos, respeitando os lapsos e as falhas em relação à norma culta da época.

61 Id., pag. 01-06.
} 
uma concepção mais interacionista, em que ele pode ser retratado como um sujeito histórico, "sendo capaz de representar seu próprio mundo e nele atuar, naturalmente como dominado" (GOMES, 2004, p.164), ou seja, não como um reflexo da vontade dos seus senhores.

Contudo, ao mesmo tempo em que consideramos os escravos agentes de seus próprios interesses, não devemos subestimar os limites que os constrangimentos estruturais impunham ao seu campo de ação (COSTA, 1998; MARQUESE, 2013). Não esquecer que, mesmo vivendo numa fazenda desconhecida do interior da província do Rio de Janeiro, cedo ou tarde, a realidade da qual eles faziam parte foi pressionada pelos efeitos das mudanças decorrentes da complexa interação entre o local e o provincial. Desse modo, as estradas de ferro, os engenhos centrais, a energia elétrica, o telégrafo, o movimento abolicionista, a defesa do trabalho livre, cada um a seu modo e todos interdependentes, faziam parte das transformações socioeconômicas do capitalismo global, do qual o Brasil era parte integrante. Em outras palavras, diante de tais forças sociais, econômicas e culturais, os sujeitos históricos dessa trama deparavam-se com a necessidade de ressignificação dos sentidos de suas relações no mundo, tendo para isso de recorrerem às experiências vivenciadas e às suas expectativas acerca do futuro.

Com o auxílio da análise materialista do discurso (PÊCHEUX, 1997; 2002; ORLANDI, 1999), a construção de nossa problematização sobre esse passado se deu a partir das sequências discursivas que recortamos de fontes históricas como periódicos, legislação, inventários e auto de perguntas da polícia. Esses documentos, respeitando as especificidades do seu gênero textual e das relações de poder das quais resultaram, foram trabalhados a partir das disputas de sentido estabelecidas entre os sujeitos sociais. Tendo em vista as condições de produção do discurso, ou seja, o vínculo entre as circunstâncias imediatas e a realidade sócio histórica (PÊCHEUX, 1997, p. 77-78), destacamos nesses documentos os seguintes elementos: a relação de forças entre os antagonistas, pois o estatuto de um discurso tem relação com o lugar social de quem fala; a relação de sentidos, a entender que um discurso sempre remete a outros discursos; e, por fim, o mecanismo da antecipação, a significar que, numa dada disputa social, em maior ou menor grau, todo sujeito tem a capacidade de se colocar no lugar do outro para pensar a sua próxima ação.

Nesse processo, consideramos, também, a formação imaginária que se encontra na base de qualquer conhecimento histórico, haja vista que não estamos lidando com o sujeito empírico, de carne e osso, mas com as imagens dele projetadas no discurso que construímos a partir dos documentos. E são essas imagens que nos permitem rastrear e "passar das situações empíricas - os lugares dos sujeitos - para as posições dos sujeitos nos discursos" (ORLANDI, 1999, p. 40) e vice-versa. Desse modo, é importante considerar que, em suas interações, os sujeitos jamais controlam completamente o fluxo do seu dizer e, como as palavras não são transparentes e mudam de sentido de acordo com o lugar social dos interlocutores, elas são um importante vestígio para nos revelar as contradições existentes.

Muito embora a formação discursiva condicione "ce qui peut et doit être dit" (HAROCHE; HENRY; PÊCHEUX, 1971, p. 102), ou seja, o que pode e deve ser dito num certo contexto, isso não significa que os sujeitos irão, necessariamente, comportar-se de acordo com o previsto e/ou prescrito por determinada formação ideológica. Devido à força do interdiscurso, ou seja, dos diversos enunciados e sentidos que circulam no mundo social, todos os sujeitos estão expostos aos conteúdos de diferentes formações. Desse modo, uma formação discursiva pode ser atravessada pelos enunciados de outras formações, o que abre espaço para as diferentes tomadas de posição do sujeito. E esse sujeito pode se identificar, contraidentificar ou mesmo se desidentificar com os conteúdos de sua formação e, também, identificar-se com os de outra formação discursiva-ideológica (PÊCHEUX, 1997, p. 213-231; INDURSKY, 2007, p. 75-87; GRANJEIRO, 2007, p. 33-45).

Nessa perspectiva, não há como o sujeito escapar do efeito de naturalização do ideológico de que ele é a origem de seu próprio dizer. Portanto, a ideologia apresenta-se como a condição para a emergência do sujeito e dos sentidos atribuídos aos seus dizeres, 
ou seja, a ideologia não oculta, "está na produção da evidência do sentido (só pode ser 'este') e na impressão do sujeito ser a origem dos sentidos que produz, quando na realidade ele retoma sentidos pré-existentes" (ORLANDI, 1998, p.16). E, para fazer deslizar o sentido do campo da linguística para o da história, podemos considerar a ideia de que a posição assumida pelo sujeito no discurso dependerá do que Thompson (1978) denomina de experiência humana, isto é, do modo como o agente interpreta tal acumulação de vivências e usa essa compreensão para o dizer/agir no mundo dentro dos constrangimentos impostos por certas condições históricas.

A relação entre língua, discurso e ideologia é uma dimensão privilegiada da experiência histórica. Para investigarmos como determinados enunciados significam para os sujeitos, precisamos considerar o texto do documento "como tendo uma materialidade simbólica própria e significativa, como tendo uma espessura semântica" (ORLANDI, 1999, p. 18) e que seja concebido no processo de disputa de significados entre os grupos sociais. $O$ caminho que percorremos na construção desses sentidos sobre o passado é sempre condicionado pela síntese de diversas variáveis que envolvem as complexas relações do historiador na construção do seu objeto de pesquisa e, como bem afirma Kosselleck (2006, p. 309-310) "na experiência de cada um, transmitida por gerações e instituições, sempre está contida e é conservada uma experiência alheia".

\section{A questão do elemento servil}

Em julho de 1878, o Congresso Agrícola, organizado pelo Ministério da Agricultura, aconteceu na cidade do Rio de Janeiro. Nele, tendo à frente o chefe do gabinete liberal, José Lins Vieira Cansansão de Sinibu, foram discutidos os principais problemas enfrentados pela grande lavoura naquele momento, sendo esse o setor que gerava a maior fonte de receitas para o Estado brasileiro (CONGRESSO AGRÍCOLA, 1878). Se, por um lado, não havia um consenso prévio a respeito do caminho para a superação dos problemas, pelo outro, a maioria dos participantes, oriunda do Centro-Sul do país, parecia estar de acordo com a ideia de que a crise resultava de uma dramática conjugação de fatores - como a necessidade de empréstimos de capitais a juros baixos, a escassez de mão de obra e a inexistência de escolas agrícolas para a formação do futuro trabalhador da lavoura e esclarecimento dos agricultores sem instrução.

Muito embora tenham demonstrado desinteresse por esse Congresso, os fazendeiros de Campos dos Goytacazes compreendiam que a Lei de 28 de setembro de 1871 (Lei do Ventre Livre), aprovada no governo conservador de José Maria da Silva Paranhos (1871-1875), colocara a escravidão com os dias contados, apanhando os grandes proprietários despreparados e deixando-os numa situação de urgência. Diversas instituições locais, como a Câmara, a Sociedade Campista de Agricultura, ${ }^{62}$ os jornais e os partidos políticos, malgrado as diferenças entre elas, defendiam a proposta de uma emancipação lenta e gradual da escravidão. Na realidade, em 1871, assim que tomaram conhecimento da Lei do Ventre Livre, centenas de fazendeiros e comerciantes locais organizaram um abaixoassinado. Esse foi remetido ao Clube da Lavoura e do Comércio, associação criada na Corte para "encaminhar a emancipação do elemento servil de maneira a resguardar os direitos dos proprietários de escravos e em ordem a evitar a ruína da riqueza pública e particular". ${ }^{63}$ No documento encaminhado, dando como causa perdida a votação na Assembleia Geral Legislativa, os abaixo assinados solicitavam que, como última salvação da lavoura, os ilustrados membros do Clube recorressem ao Senado para que o mesmo rejeitasse o perigoso projeto de lei.

A formação discursiva dominante, conciliando a defesa da civilização com os interesses da lavoura, sustentava uma série de enunciados inter-relacionados: o de que a

\footnotetext{
62 Essa associação, representante dos grandes fazendeiros locais, era comandada pelos Ribeiro de Castro e Carneiro da Silva, grandes proprietários de terras e escravos. Na década de 80 , foi a responsável pela entrada de dezenas de famílias imigrantes no município.

63 Diário do Rio de Janeiro, n. 196, p. 1, 17 jul. 1871. Hemeroteca Digital, Biblioteca Nacional, Rio de Janeiro.
} 
escravidão, feito uma herança maldita, só poderia ser extinta de modo gradual, portanto, era uma necessidade irresistível do sistema; a de que a liberdade legal do negro esbarrava no sagrado direito de propriedade; de que os favores dos senhores poderiam construir um sentimento de liberdade para os seus cativos, "taes como facilitar e proteger os casamentos, respeitar a família, dar gratuitamente pequenos prazos de terra para a sua pequena lavoura, e auctorizar a formação de pecúlios" 64 ; de que a liberdade, não sendo acompanhada da devida educação, condenaria o ex-escravo ao vício; e, por fim, a certeza da superioridade racial, moral e intelectual do imigrante europeu em relação aos negros.

\section{A Sociedade Agrícola do Queimado}

Manoel Antônio Ribeiro de Castro, barão de Santa Rita, nascido em Braga, Portugal, no ano de 1767, veio para o Brasil em 1789, quando tinha vinte e dois anos de idade. No ano de 1790, como dono de loja de tecidos, instalou-se na vila de São Salvador dos Campos dos Goytacazes num momento em que, ligada ao circuito econômico do Rio de Janeiro, a região se encontrava em franca expansão da cultura do açúcar (PIZARRO, 1820, p. 119; OLIVEIRA, 1999; p. 61-62; SOARES, 2009, p. 33-50). Então, em 1797, ele se aproveitou dessa conjuntura para adquirir algumas terras e se dedicar à lavoura escravista, onde acumulou uma boa fortuna e realizou o sonho acalentado por muitos outros homens da comunidade: o de ser senhor de engenho.

Nas primeiras décadas do século XIX, já na condição de capitão-mor e proprietário, Manoel Antônio Ribeiro de Castro era uma referência de "homem bom" na rede de relações da elite política local, tendo sido um dos anfitriões do imperador Pedro II quando o mesmo visitara a cidade em 1847, "gentileza" que the rendera o prestigiado título de barão. Ao falecer, em 1854, com oitenta e sete anos, deixou para a esposa e os filhos um patrimônio formado por terrenos, casas, chácaras, fazendas, dinheiro, animais e escravos, tudo avaliado no total de 301:285\$260 rs (trezentos e um contos, duzentos e oitenta e cinco mil e duzentos e sessenta réis). ${ }^{65} \mathrm{E}$, ao final da partilha, subtraindo o valor das dívidas deixadas pelo falecido, ficava uma quantia de 286:309\$900 rs (duzentos e oitenta e seis contos, trezentos e nove mil e novecentos réis).

Em $1^{\circ}$ de julho de 1866, o comendador Julião Ribeiro de Castro (um dos filhos do falecido barão de Santa Rita), aos quarenta e oito anos, então subdelegado do $1^{\circ}$ distrito da freguesia de Santa Rita, junto com o seu filho, José Julião Ribeiro de Castro, criou uma sociedade agrícola de cultura e fabrico de cana na fazenda do Queimado. No ano de sua criação, o capital dessa empresa era de 180:000\$000 rs, referente ao valor das máquinas, terras, escravos, animais, prédios; entre outros. Em 1879, treze anos depois de sua criação e dois após a suposta tentativa de sublevação dos escravos na dita fazenda, se levarmos em consideração as benfeitorias e os bens acrescidos, o valor do patrimônio saltou para a quantia de 278:900\$000 rs. ${ }^{66}$

Quando do retorno dos liberais ao poder, em 1878, depois de dez anos de domínio conservador, foi particularmente difícil para os novos governantes responderem a tantas demandas. Dentre os problemas enfrentados, destacaremos a dívida pública decorrente dos empréstimos para financiar a Guerra do Paraguai (1864-1870) e a estagnação da grande lavoura de norte a sul do país. Essa crise ocorreu em função do problema da mão de obra e do escasso capital para financiar e modernizar a produção agrícola, tendo em vista que a concorrência internacional não dava tréguas, e a depressão global do capitalismo dos anos

\footnotetext{
${ }^{64}$ Monitor Campista, n. 62, p. 1, 6 jun. de 1871. Hemeroteca periódicos, Arquivo Público Municipal Waldir Pinto de Carvalho, Campos dos Goytacazes, Rio de Janeiro.

65 Termo de despacho, avaliação e cálculo de partilha dos bens do Sr. Manoel Antônio Ribeiro de Castro. Juízo Municipal da cidade de Campos dos Goytacazes, ano de 1871. Hemeroteca Inventários. Arquivo Público Municipal Waldir Pinto de Carvalho, Campos dos Goytacazes, Rio de Janeiro.

${ }_{66}$ Auto de requerimento para dissolução e partilha de sociedade agrícola estabelecida entre Julião Ribeiro de Castro e José Julião Ribeiro de Castro. Juízo Municipal da cidade de Campos dos Goytacazes, 4ํㅡㄴorio, ano de 1879. Hemeroteca de inventários. Arquivo Público Municipal Waldir Pinto de Carvalho, Campos dos Goytacazes, Rio de Janeiro.
} 
1870 afetou principalmente a agricultura, sendo esta "a vítima mais espetacular desse declínio dos lucros - na verdade, alguns de seus setores foram os que sofreram depressão mais profunda de toda a economia - e aquela cujo descontentamento teve consequências políticas mais imediatas e de maior alcance" (HOBSBAWM, 1988, p. 59-60).

De fato, os sócios, pai e filho, tentaram acompanhar as transformações econômicas em curso no país e, ao mesmo tempo, mantiveram o trabalho escravo em seus domínios enquanto lhes foi possível. No final da década de 1870 e, principalmente, ao longo dos anos 1880 , numa tentativa de se ajustar aos novos tempos, a empresa agrícola do Queimado recebeu um grupo de oito famílias açorianas para se estabelecer como colonos em suas terras, experiência que, de início, mostrou-se um tanto problemática. Paralelo a isso, eles trabalhavam na instalação de um Engenho Central, mobilizados pela crença de que esse empreendimento, consolidador do trabalho livre e produtor de grandes riquezas, além de incentivar a superação dos métodos atrasados, permitiria a divisão social mais racional do trabalho em que, conforme o discurso da tipologia ideal do governo, os agricultores seriam apenas agricultores e os fabricantes apenas fabricantes. ${ }^{67}$

Aprovada pelo Parlamento, a Lei ํㅡ 2687, de 1875, autorizava o Governo, via Banco de Crédito Real, garantir juros de $7 \%$ para aqueles empréstimos de até trinta mil contos das companhias que se propusessem a criar um engenho central para a produção de açúcar. No entanto, com recursos próprios, em agosto de 1880, o comendador, seu filho e irmão inauguraram o Engenho Central do Queimado. O feito foi celebrado por um periódico local como fruto da perseverança e esforços de seus ilustres proprietários, que buscaram "introduzir nela todos os melhoramentos modernamente conhecidos para o aperfeiçoamento da cultura da canna e do assucar em sua fazenda, conseguirão por fim torná-la em uma boa usina". 68

No período que vai de 1850 a 1881, houve uma sensível racionalização e implementação técnica da produção de açúcar na região (FARIA, 1985), muito embora ficasse aquém do que um especialista como o Sr. Gustavo Trinks, diretor da Sociedade Central de Imigração, acreditava ser possível produzir caso houvesse uma combinação de meios técnicos, gerência eficaz e ampliação da mão de obra qualificada. ${ }^{69}$ De qualquer modo, em que pese a crítica à tímida otimização das técnicas de produção, verificamos o crescimento dos engenhos a vapor, o decréscimo dos engenhos por tração animal e o surgimento dos engenhos centrais, financiados por capital privado e/ou subsidiada pelo governo. ${ }^{70}$ Portanto, algumas dessas mudanças colaboraram para a incrementação da produção de açúcar e da aguardente no decênio de 1872 a 1881, cuja média foi de $16.756,632 \mathrm{~kg}$, superior à do decênio de 1862 a 1871, em que a média havia sido de $13.683,834 \mathrm{~kg}^{.1}$

A iniciativa da família Ribeiro de Castro corrobora a proposição de Pereira (2012) sobre certo dinamismo dos grandes produtores e usineiros nas décadas que antecederam à abolição da escravatura. De fato, como afirma o autor, a proximidade do fim da escravidão não representou uma derrocada econômica para os grandes senhores locais, pelo contrário, eles buscaram meios de garantirem e ampliarem os seus ganhos. Portanto, ao contrário do

\footnotetext{
67 BRASIL. Ministério da Agricultura. Secretaria de Estado dos Negócios da Agricultura, Commercio e Obras. Relatório do ano de 1881, Engenhos centrais, p. 33-34. Disponível em: <http://brazil.crl.edu/bsd/bsd/u1963/>. Acesso em: 23 mar. 2018.

${ }^{68}$ Monitor Campista, n. 178, p. 3, 11 ago. de 1880. Hemeroteca periódicos, Arquivo Público Municipal Waldir Pinto de Carvalho, Campos dos Goytacazes, Rio de Janeiro.

${ }^{69}$ Sobre essa questão, o Sr. Gustavo Trinks lançou um trabalho no qual comparava a pequena produtividade da indústria açucareira brasileira com a das estrangeiras, o que gerou diversos protestos entre os estudiosos locais. In: ALVARENGA, João de. Almanak mercantil, industrial, administrativo e agrícola da cidade e município de Campos. Campos: Monitor Campista, 1881, p. 119 a 128. Hemeroteca periódicos, Biblioteca Nacional, Rio de Janeiro.

70 ld., 1885, p. 52.

71 Id., 1885, p. 56.
} 
que afirma Faria (1985) sobre a crise do período, a baixa do preço do açúcar e a elevação do preço da mão-de-obra não teriam afetado a todos, mas, principalmente, "os plantadores, sitiantes, arrendatários e lavradores" (PEREIRA, 2012, p. 226).

\section{O plantel da fazenda do Queimado}

No ano de 1881, o município de Campos dos Goytacazes possuía uma população de 89.120 habitantes, sendo 57.000 livres e 32.120 escravos, destes últimos, 28.292 nascidos no Brasil e 3.828 na África. ${ }^{72} \mathrm{Na}$ freguesia de São Salvador, local em que se encontrava o engenho do Queimado, viviam 7.910 cativos, sendo 4.040 homens (1.397 com idade de 10 a 20 anos; 1.491 de 20 a 40 anos; 1.152 de 40 a 70 anos) e 3.870 mulheres (1.202 com idade de 10 a 20 anos; 1.295 de 20 a 40 anos; 1.371 de 40 a 60 anos). Desse contingente, 552 eram casados, 123 viúvos e 7.235 solteiros. No concernente ao exercício da profissão, 506 se dedicavam a diversos ofícios, 4.739 à lavoura, 891 aos serviços domésticos e 2.074 às atividades de profissão não definida. Dos cativos dessa freguesia, apenas 20 pessoas sabiam ler, o que representava $0,25 \%$ do contingente total de escravos, bem diferente dos $42,29 \%$ dos livres que sabiam ler. ${ }^{73}$

Esses dados, obtidos no Almanaque Mercantil, Industrial, Administrativo e Agrícola, são aproximados e baseados em fontes do poder público, havendo muitas lacunas e distorções, como no exemplo do silêncio sobre a população com menos de 10 anos e mais de 70 anos. Na realidade, as informações divulgadas por esse documento eram voltadas para os comerciantes e homens de negócio, como prova de ilustração e progresso do local. Contudo, muito embora a realidade fosse bem mais complexa do que supunha o Almanaque, interessa-nos que essa representação do município tenha parecido plausível para os cidadãos que o assinavam e queriam se ver representados nele.

Para o ano de 1877, ano em que ocorreu a denúncia de sublevação, não temos o número do total de escravos que vivia na fazenda do Queimado. Contudo, em 1879, por conta da morte da esposa do major José Julião, houve a "dissolução" da sociedade agrária do pai com o filho para proceder a divisão da herança entre as crianças. Nos autos do processo, o comendador Julião Ribeiro de Castro solicita que o original de matrícula dos seus escravos seja "desentranhado" da partilha referente à sociedade, um montante de cento e oitenta registros, isto é, cento e oitenta cativos, nos quais estavam misturados os dele, do filho e da esposa. Portanto, as considerações que faremos adiante terão como referência esse plantel, mesmo sabendo que, no total, a considerar outras propriedades pertencentes à família, a quantidade de escravos poderia ser bem maior do que a declarada.

$\mathrm{Na}$ fazenda do Queimado, havia 180 escravos registrados. Desse total, $45 \%$ tinham até 21 anos de idade e 55\% tinham entre 21 e 65 anos. Dos menores de idade, $48 \%$ eram do sexo masculino e $52 \%$ do sexo feminino. Dos adultos, $49 \%$ eram do sexo masculino e $51 \%$ feminino, sendo $42 \%$ casados e $58 \%$ solteiros e a média de idade entre os casados era de 48 anos. Dos 157 escravos considerados em idade para o trabalho, a partir dos 8 anos, $62 \%$ trabalhavam na roça, $15 \%$ em atividades como as de maquinista, carpinteiro, pedreiro, carreiro, ferreiro, hortelão e campeiro, $17 \%$ dedicados ao serviços domésticos, como os de mucama, pajem, engomadeira, cozinheiro, copeiro, lavadeira e, por fim, $6 \%$ tinham entre 8 e 10 anos, mas não trabalhavam em nenhuma atividade. Enfim, do total de escravos, 18\% eram de nação - sendo o mais novo deles com 46 anos e o mais velho com 65 anos, $21 \%$ eram naturais do próprio município e $61 \%$ denominados crioulos. ${ }^{74}$

\footnotetext{
72 Id., 1881 , p. 119 a 128.

73 Id., 1881 , p. 119 a 128.

${ }^{74}$ Auto de requerimento para dissolução e partilha de sociedade agrícola estabelecida entre Julião Ribeiro de Castro e José Julião Ribeiro de Castro. Juízo Municipal da cidade de Campos dos Goytacazes, 4ํㅡㅁortório, ano de 1879. Hemeroteca de inventários. Arquivo Público Municipal Waldir Pinto de Carvalho, Campos dos Goytacazes, Rio de Janeiro.
} 
Nazara, João Macahe, Malaquias, Rufina, pretos, fulos, pardos, solteiros, casados, viúvos, carpinteiros, roceiros, cozinheiros, de nação ou crioulos, com filhos ou sem filhos, de todas as idades, dezenas de núcleos familiares consanguíneos e grupos de amigos viviam nas senzalas do engenho do Queimado. É desse universo que emerge a figura de Manoel "Çacramento", o escravo que sabia ler e lia jornal para os seus companheiros de cativeiro. Segundo as imprecisas estatísticas da freguesia de São Salvador, ele era um dos 20 cativos que sabiam ler. Mas, afinal, quem o alfabetizara?

\section{Escravos, leitura e a sublevação no Queimado}

Abordar a história do letramento do escravo no Brasil imperial é lidar com um processo persistente de exclusão e violência simbólica. Como propõem Fonseca (2007) e Bastos (2016), durante muito tempo, tanto na historiografia quanto nas fontes, identificamos os silêncios sobre o tema da educação dos negros. Mas, também como aponta Barros (2015) no seu estado da arte sobre o assunto, esse quadro vem, aos poucos, modificandose nas últimas décadas. Assim, trabalhos como o de Fonseca (2002), Paiva (2003), Lopes (2015), entre outros, com diferentes questões e abordagens, têm procurado desmistificar a ideia de que "a população negra não teve acesso à escola antes da democratização do ensino básico, ocorrida em meados do século XX" (Barros, 2015, p. 23), assim como também demonstrar a possibilidade de alfabetização do negro para além do espaço escolar.

No caso específico deste trabalho, interessa-nos demonstrar que, mesmo não tendo acesso à escola, o escravo Manuel do Sacramento aprendera a ler e escrever com outro escravo da fazenda - o velho Basílio, africano, viúvo que cuidava da horta do engenho. ${ }^{75}$ Não conseguimos descobrir com quem este escravo mais velho aprendera a ler e por qual razão ensinara ao outro e não aos demais. Esse é um daqueles silêncios das fontes em que o argumento sobre a exploração dos escravos dentro do sistema nos ajuda a entender a sua exclusão do letramento. Contudo, os não ditos também podem ser inferidos a partir das disputas de sentidos entre os senhores e os seus escravos, em razão daquilo que eles escondem e revelam em seus discursos, sempre se relacionando com a posição de cada um deles na hierarquia social (ORLANDI, 1995).

O auto de perguntas é um desses documentos que nos dá acesso ao discurso dos interrogados a partir da escuta e das palavras do interrogador e/ou escrivão. Portanto, é um dizer marcado pela relação desigual de poder numa interação face a face dos escravos com as autoridades policiais. Por mais que existam as estratégias de antecipação das quais os sujeitos inquiridos se utilizam, tendo em vista os seus objetivos e o que eles imaginam ser os objetivos do seu inquisidor, em última instância,no papel permanecerá a escolha daqueles que têm o poder para decidirem o que deve e o que não deve ficar registrado para a posteridade. Contudo, isso não significa que essas escolhas serão realmente eficazes em estabelecer certa versão do passado, haja vista quantos significados clandestinos nos trazem as palavras e quantas interpretações são feitas do que ficou registrado.

As respostas dos acusados (Manoel, Marcos, Matheus, Marcolino, Apolinário e Cesário) sugerem que, em linhas gerais, a história da combinação entre os escravos se dera do seguinte modo. Entre os meses de abril e maio de 1877 , eles teriam se reunido duas vezes para deliberarem sobre a reivindicação que fariam ao seu senhor, sendo o primeiro encontro na roça e o segundo na cocheira. Nessa última reunião, numa terça feira, 08 de maio, entre às sete e oito da noite, decidiram que, na manhã seguinte, procurariam pelo comendador para informar que, se não melhorassem as condições de vida e/ou fossem pagos pelo seu trabalho, eles não voltariam mais para o eito. Ao que tudo indica, nesse meio tempo ou, quem sabe, antes mesmo disso, a combinação foi denunciada.

Então, na quarta-feira, logo cedo, quando os escravos ainda dormiam na senzala, antes de ser realizada a revista dos feitores pela manhã, a força policial veio para conduzilos à delegacia. O responsável pelo encaminhamento foi o Sr. delegado de polícia, o tenente

\footnotetext{
75 Id. ibid.
} 
coronel Antônio Rodrigues da Costa, ex-professor de álgebra e geometria que, na juventude, havia sido um liberal exaltado e, segundo os seus críticos, com a passagem do tempo e a mudança de seus interesses, tornara-se um conservador enragé. ${ }^{76}$ Como a fazenda ficava há poucos quilômetros do centro da freguesia de São Salvador, é bem possível que, em poucos minutos, tenham chegado à sede da polícia.

Os acusados, à exceção de Cesário que era vigia e/ou feitor, não negaram a participação na dita combinação. Considerando-se as relações de poder que modulam os enunciados num interrogatório, nas respostas de três deles, como motivos para a reclamação, constatamos alusões às péssimas condições de vida e de trabalho em que viviam. Assim, "por ser o serviço muito e o alimento insufficiente e igualmente a roupa", e "por não ter bom tratamento"77, eles resolveram ir ao seu proprietário para, conforme a variedade dos verbos (entender, pedir, declarar, representar) na síntese dos depoimentos, sobre a questão.

Podemos supor, então, que, de todas as maneiras, os acusados tentaram demonstrar que não se tratava de um delito (termo técnico da polícia), mas de uma combinação (termo referente aos escravos) para levarem ao comendador os seus justos pedidos. Por meio do mecanismo de antecipação discursiva, Matheus, ao operar com a possível lógica do seu interlocutor sobre a rebeldia escrava, parecia buscar convencê-lo de que não se tratava de um delito, pois se "tivessem más intenções a força da polícia não os encontraria dormindo". ${ }^{78}$ Por sua vez, Manoel e Apollinário, reafirmando a convicção de que lutavam pelo que thes parecia justo, disseram que resistiriam a todo custo, ainda que alguém lhes opusesse a pau. Como se vê, o modo de se nomear o acontecimento (combinação versus delito/insurreição) aponta para a inscrição em lógicas e estratégias discursivas diferentes.

Três dos escravos - Matheus, Marcolino e Apollinário - destacaram as razões referentes às péssimas condições de vida e de trabalho que os levaram àquela combinação. $\mathrm{Na}$ base dessa reclamação, encontrava-se uma expectativa de que os senhores respondessem às suas necessidades, fruto da interdependência desses sujeitos sociais dentro do engenho, identificável no discurso sobre as atribuições que cabiam a cada um deles nas tensas interações da conjuntura de crise do escravismo. De todo modo, como já foi apontado pela historiografia sobre a dinâmica das relações escravistas na região sudeste:

As tensões tradicionais entre senhores e escravos, que tendiam a se resolver no campo do costumeiro (e, portanto, de relações privadas de poder), transbordavam de forma progressiva para a esfera do poder público, num contexto ideológico que não tornava mais possível a tradicional e limitada arbitragem em nome do bem comum. (MATTOS, 1998, p. 191).

Assim, em seus depoimentos, eles operavam com a concordância de que havia práticas legítimas e ilegítimas no tratamento recebido de seu proprietário, isto é, havia o que era aceitável e o que era inaceitável na natureza daquela relação. Ou bem o senhor oferecia as condições adequadas de trabalho ou, então, que lhes desse a liberdade para tratarem de suas próprias vidas. $E$, caso se negasse a fazê-lo, eles iriam à cidade reclamar à Câmara Municipal ou à Justiça. E , no município, a fazenda do Queimado não era a única em que os escravos se reuniram para lutar ou buscar ajuda de terceiros contra os maus tratos cotidianos, a exemplo de um grupo de dezesseis escravos (entre homens e mulheres) que

\footnotetext{
${ }^{76}$ Monitor Campista, n. 233, p. 2, 7 out. 1885. Hemeroteca periódicos, Arquivo Público Municipal Waldir Pinto de Carvalho, Campos dos Goytacazes, Rio de Janeiro.

77 Auto de perguntas feitas aos escravos do Comendador Julião Ribeiro de Castro. Delegacia de Polícia do Termo de Campos, 09 de maio de 1877, pag. 05. In: Arquivo Público Municipal Waldir Pinto de Carvalho, Campos dos Goytacazes, Rio de Janeiro.

78 Id., pag. 03.
} 
se levantou para denunciar a brutalidade da endividada família dos Barroso Siqueira e foi bater à porta de um conhecido solicitador do Partido Conservador em busca de proteção. ${ }^{79}$

No caso da combinação do Queimado, há ainda uma importante questão a ser considerada. A interpretação feita por Manoel "Çacramento" e seus amigos do enunciado que eles leram no Monitor Campista: de que o trabalho era livre e, como tal, deveria ser remunerado. Nesse caso, como bem sugere Chartier (2011, p. 233), o ato de ler deve ser pensado a partir das especificidades de cada época e dentro das condições de leitura dos grupos sociais. No caso específico do plantel do Queimado, cremos que era uma leitura coletiva com sentido construído em conjunto, ainda que esse sentido fosse utilizado de modo diferente por cada um dos participantes. Assim, podemos destacar aquilo que Paiva (2003, p. 2) chama de leitura indireta, "cujas operações básicas foram escutar, reproduzir e reelaborar a partir do contexto e de valores culturais", enfim, das condições de produção do discurso encontradas naquela conjuntura.

Nos autos, a transcrição faz parecer que, tanto para Manoel quanto para Marcos, o enunciado do trabalho livre remunerado era um argumento de autoridade que servia para justificarem a sua ação. Já os demais só fizeram alusão a esse enunciado de maneira complementar ou, então, quando inquiridos sobre o tema. Esse detalhe aponta para diferentes modos como cada um deles pode ter se apropriado do sentido dessa leitura. Manoel e Marcos são apresentados como mais assertivos na defesa desse direito à liberdade, posicionando-se numa formação discursiva liberal. Por sua vez, os outros colegas, fosse por estratégia ou descrença de que tal argumento realmente tivesse efeito sobre os seus senhores, defendiam a ideia de que as expectativas daquela relação estavam sendo quebradas por uma de suas partes, o que os colocava sob o abrigo dos antigos costumes, determinando o que era aceitável ou não na relação dos senhores com os seus escravos (CHALHOUB, 1990).

Interessante perceber que a leitura do jornal foi uma questão a qual o delegado retornou com todos os entrevistados, como que dedicando uma atenção especial à interpretação de um texto no desencadeamento do "delito", haja vista o escravo Manoel ter afirmado "que tinha lido no Monitor por onde se convencia que érão livres". ${ }^{80}$ Num primeiro momento, podemos imaginar que se tratava apenas de um interrogatório para distribuir o peso das responsabilidades entre os escravos, porém havia algo mais na insistência do Sr. delegado. $E$, como veremos adiante, o evento da fazenda não estava fora das disputas ocorridas em outros espaços políticos e sociais dos quais o engenho do Queimado fazia parte.

Se, como propõe Pêcheux (2007, p. 26), uma formação discursiva condiciona "o que pode e deve ser dito" numa certa conjuntura, podemos considerar que a formação discursiva escravista comporte a reivindicação de um escravo por um melhor tratamento, desde que não altere a sua posição na relação hierárquica com o seu senhor. Contudo, o mesmo não se aplica a um escravo que argumenta ser livre e, como tal, merecedor de ganhar jornal. Esse enunciado do sujeito ser livre e o seu trabalho remunerado, ideia recorrente numa formação discursiva liberal, é um interdiscurso que atravessa a cena e possibilita a alguns dos escravos utilizá-lo como argumento de autoridade para se contraidentificarem com a lógica escravocrata e colocarem-se em outra posição dentro do discurso.

Com efeito, em Campos dos Goytacazes, ao longo do século XIX, não faltaram exemplos de revoltas, quilombos, fugas, assassinatos, suicídios, entre outras formas de resistência dos cativos ao arbítrio dos seus senhores (LARA, 1988; LIMA, 1981; RIBEIRO, 2012, LEMOS, 2018.). E a luta por liberdade não se restringia à ideia do trabalho remunerado da formação ideológica liberal, mesmo porque o trabalho escravo não era uma realidade incompatível com a acumulação do capitalismo global (TOMICH, 2011), assim

\footnotetext{
79 Monitor Campista, n. 103, p. 3, 11-12 mai. 1877. Hemeroteca periódicos, Arquivo Público Municipal Waldir Pinto de Carvalho, Campos dos Goytacazes, Rio de Janeiro.

80 Auto de perguntas feitas aos escravos do Comendador Julião Ribeiro de Castro. Delegacia de Polícia do Termo de Campos, 09 de maio de 1877, pag. 02. In: Arquivo Público Municipal Waldir Pinto de Carvalho, Campos dos Goytacazes, Rio de Janeiro.
} 
como também parte dos escravizados poderia juntar um pecúlio com o seu trabalho. De todo modo, esse enunciado dos braços livres, emerso das páginas do jornal sobre as mudanças dos novos tempos, foi apropriado pelos escravos para uma significação que extrapolava o sentido corrente na sua formação discursiva "de origem".

Portanto, na síntese dos depoimentos, o enunciado dos braços livres se relacionava com o direito a melhores condições de vida e trabalho, alimentos e repouso, estabelecimento de limites ao arbítrio do senhor e garantias da Justiça. Aquele era um momento em que a discussão sobre a crise do trabalho servil, o incentivo à entrada dos imigrantes e o fundo de emancipação dos escravos se encontravam na ordem do dia. Se, como afirma Mattoso (1982, p. 187), ser libertado era, via de regra, "uma questão de dinheiro, pois o escravo era uma mercadoria com o seu valor venal", também poderíamos inferir sobre as possibilidades desses cativos do Queimado de juntarem um pecúlio.

Não é possível determinar quantos escravos, realmente, participariam da ida à casa do senhor, pois cada acusado se referiu a um número diferente ou falou de modo genérico. Marcos afirmou que todos faziam parte da combinação. Marcollino, sem citar nomes, disse ter combinado com seis parceiros para irem ao seu senhor. Manoel, Apollinario e Matheus, também sem citarem nomes, tinham como certa a participação dos seus companheiros de trabalho. Por sua vez, Cezário, encarregado de vigiar os seus colegas, "disse que estando de ronda, observou que toda a escravatura da fazenda em excepção de seo pai, Bartholomeo, João Antonio, Quintiliano, Bento e Claudio seguião para a coxeira onde se estavão reunindo". ${ }^{81}$ Então, para não ser comprometido, pediu aos outros que esperassem pela manhã para representarem ao senhor, no que todos tinham concordado.

Observamos que, por um lado, apesar de ser encarregado de vigiar os outros, Cesário falava a partir do mesmo lugar empírico dos seus colegas de cativeiro e, por essa razão, pôde pedir o favor de não o comprometer. Por outro lado, pelo cargo que ocupava, devia gozar da confiança de seu senhor que, possivelmente, dele esperava lealdade. Ao narrar o evento como se não fizesse parte da combinação, assume uma posição discursiva de testemunha, como se fosse possível não ser responsabilizado por uma reunião daquele tamanho ter se passado sem reprimendas no horário de sua ronda. É possível que, como propõe Ribeiro (2012), ele tenha ganhado tempo para denunciar os seus companheiros. Mas, segundo o jornal, não havia sido ele o delator: "Segundo nos informão, um dos pagens do Sr. comendador Julião foi que, como fiel escravo, deu notícia da sinistra pretensão dos outros". 82

De qualquer modo, assim como fizeram Quintiliano (casado, 36 anos, carreiro e quatro filhos) e Bartholomeu (casado, 40 anos, copeiro e quatro filhos) ${ }^{83}$, é bem possível que outros escravos (fossem homens ou mulheres) também não tivessem participado da ação reivindicatória porque eram casados, domésticos e/ou tivessem filhos. O que não significava que não soubessem do que estava acontecendo ou não apoiassem (SLENES, 2011, p.60), considerando-se que seria praticamente impossível guardar segredo naquele microcosmo, tendo em conta uma reunião da qual participara grande número de pessoas. $E$ nada impede que, ao descobrirem que os seus nomes não se encontravam na lista da junta classificadora de emancipação, alguns escravos casados se sentissem frustrados.

Ao final do auto de perguntas, o delegado chegou à seguinte conclusão: "Não tendo havido começo de execução de delicto, por haver a policia prevenido a tempo, não tem lugar o procedimento por tentativa; archive-se estes autos, dando-se traslado aos donos dos

\footnotetext{
81 Id., pag. 04.

82 Monitor Campista, n.103, p. 3, 11 e 12 mai. 1877. Hemeroteca periódicos, Arquivo Público Municipal Waldir Pinto de Carvalho, Campos dos Goytacazes, Rio de Janeiro.

${ }^{83}$ Auto de requerimento para dissolução e partilha de sociedade agrícola estabelecida entre Julião Ribeiro de Castro e José Julião Ribeiro de Castro. Juízo Municipal da cidade de Campos dos Goytacazes, 4ํㅡㅁortório, ano de 1879. Hemeroteca de inventários. Arquivo Público Municipal Waldir Pinto de Carvalho, Campos dos Goytacazes, Rio de Janeiro.
} 
escravos, se o exigirem". ${ }^{84} \mathrm{E}$ o que teria acontecido aos seis acusados? No processo de partilha da fazenda em 1879, nós localizamos alguns nomes, mas não é possível afirmarmos que realmente sejam eles, pois o auto de perguntas fornece poucas informações para identificá-los com maior precisão.

\section{As disputas políticas e o elemento servil}

No ano de 1876, houve eleição para vereador, juiz de paz e eleitores em todo o Império. No município de Campos dos Goytacazes, o resultado foi a vitória esmagadora do Partido Conservador. Esse mandato, cujo exercício seria de 1877 a 1880, iniciava-se, justamente, no último ano do Gabinete conservador do Duque de Caxias (25 de junho de 1875 a 05 de janeiro de 1878). Como de uso, no esquema das alianças políticas entre a classe senhorial, a elite política local, regional e nacional, os importantes cargos da administração/ordem pública, como os de delegados e juízes, estavam distribuídos entre os correligionários daquele partido que se encontrava no poder. Portanto, o delegado tenente coronel Antônio Rodrigues da Costa, filiado do Partido Conservador, além de ser engenheiro da prefeitura, exercia o cargo de delegado de polícia, sendo figura militante do Partido Conservador no segundo maior colégio eleitoral da província.

Os liberais locais, derrotados nas eleições de 1876 (elegeram apenas três dos nove vereadores, não elegeram o juiz de paz e foram minoria na eleição dos eleitores) ${ }^{85}$, tinham no Monitor Campista uma plataforma de onde faziam circular os seus discursos sobre o progresso social, a moralização da política e a necessidade de reforma constitucional. $O$ proprietário e redator desse jornal, o bacharel Domingos de Alvarenga Pinto, junto com os seus correligionários liberais, atribuiu essa derrota ao que chamou de os métodos violentos e fraudulentos dos conservadores. $E$, em seu modo de ver, esses conservadores, representantes dos fazendeiros e negociantes, contavam com o apoio incondicional da justiça e da polícia, especialmente do delegado Antônio Rodrigues da Costa, homem de ambição política que, nas eleições, cumpria o papel de "amedrontar e perseguir o povo a ferro e fogo". 86

Por sua vez, o Diário de Campos, considerado a plataforma dos governos e dos conservadores da cidade, pertencente ao juiz municipal, Sr. Abreu Lima, tinha como redatores o próprio proprietário do jornal e o delegado Rodrigues da Costa. Nota-se, então, que a guerra entre as facções se dava em vários níveis da vida social e em relação a diversos temas, a exemplo da discussão sobre a crise do elemento servil. Todavia, nada aproximava mais um liberal de um conservador do que os seus posicionamentos sobre a escravidão, mesmo porque " a preservação da escravidão no centro da economia e da sociedade imperiais deveria ser vivida e entendida por todos como a condição da preservação da unidade e soberania do Império" (MATTOS, 1987, p. 250). Assim, os argumentos locais, com algumas diferenças, partiam de uma matriz comum: a escravatura era uma nódoa para a civilização, mas, em tão curto espaço de tempo, não havia como abrir mão dessa forma de trabalho sem desrespeitar a propriedade e colocar em risco o próprio projeto de nação.

Nesses termos, como discute Carvalho (1998, p. 61) acerca das dificuldades impostas pela escravidão ao progresso do país, a liberdade não era vista como um assunto de ordem privada ou do indivíduo, mas "um problema público, era a questão da construção da nação". Nota-se, então, que, para os mais destacados pensadores que discutiram o tema, os interesses da nação poderiam ser pensados como mais próximos do interesse do Estado ( ao modo do bispo Azeredo Coutinho), dos proprietários (ao modo de José de

\footnotetext{
${ }^{84}$ Auto de perguntas feitas aos escravos do Comendador Julião Ribeiro de Castro. Delegacia de Polícia do Termo de Campos, 09 de maio de 1877, pag. 06. In: Arquivo Público Municipal Waldir Pinto de Carvalho, Campos dos Goytacazes, Rio de Janeiro.

85 Os resultados dessas eleições estão distribuídos nas publicações do Monitor Campista de setembro a dezembro de 1876.

${ }^{86}$ Monitor Campista, n. 1, p. 2, 1 a 3 jan. 1877. Hemeroteca periódicos, Arquivo Público Municipal Waldir Pinto de Carvalho, Campos dos Goytacazes, Rio de Janeiro.
} 
Alencar) ou, ainda, de uma autêntica república socialmente liberal (ao modo de José Bonifácio e Joaquim Nabuco) (CARVALHO, 1998 , p. 61). Fosse conservadora ou liberal, a classe senhorial local sobre a qual estamos falando estava bem mais próxima da concepção de Alencar do que a de Bonifácio e Nabuco acerca do que ela entendia como interesse nacional.

Não por menos, algumas notícias sobre a escravidão que contrariavam o interesse nacional eram utilizadas pelas facções políticas em seus respectivos jornais para atacarem o opositor e, por tabela, fidelizarem os seus leitores-eleitores. Segundo os liberais, no caso do evento ocorrido na fazenda do Queimado, o delegado teria escrito em seu jornal que o plano de sublevação dos cativos ocorrera porque os jornais, entre eles o Monitor, publicaram a lista da junta classificadora na qual constavam os nomes dos escravos que seriam libertos com os recursos do fundo de emancipação, soando como um incentivo à revolta dos não contemplados. ${ }^{87}$ No entanto, como pudemos constatar, no auto de perguntas não havia nenhuma passagem em que os acusados falassem sobre a leitura da lista e a decisão de se mobilizarem por conta dela.

É possível que, conforme afirmou o delegado, os escravos tenham lido a lista com os nomes daqueles que poderiam ser libertados pelos fundos? Nos meses imediatos que antecedem o evento de maio de 1877, não localizamos a publicação da referida lista citada no debate entre conservadores e liberais. Porém, em 12 de dezembro de 1876, a Junta de Classificação de escravos, em conformidade com o Artigo $2^{\circ}$ do Decreto $n^{\circ}$ 6341, de 20 de setembro de 1876, havia publicado uma lista em que, entre dezenas de nomes, constavam os de dois escravos da fazenda do Queimado que seriam libertados: Soter e Peregrino ambos casados com pessoas livres e pais de filhos menores de 12 anos. ${ }^{88}$ Essa notícia sobre a alforria dos dois repercutiu na fazenda do Queimado? Sim, é possível que muitos tenham ficado sabendo e, de certo modo, essa novidade tenha concorrido para aumentar a certeza desses escravos sobre a interpretação a ser dada aos enunciados do jornal.

\section{Considerações finais}

No auto de perguntas que nos dá acesso à acusação, os escravos disseram que foram incentivados à combinação pelas duras condições de trabalho e porque Manoel do "Çacramento" teria lido no jornal que os braços eram livres e, como livres, deveriam ser remunerados. Até, então, esses escravos, norteados pelos costumes que estabeleciam o que era aceitável ou não em sua relação com o senhor, apoderaram-se de um enunciado liberal para reivindicarem os seus direitos. Esse posicionamento, além de expressar a contradição entre o lugar "real" do agente (a condição de escravo) e a sua posição no discurso (sujeito portador de direitos formais), aponta para o fato de que os escravos construíam argumentos que primavam por diferentes visões sobre os limites da escravidão vivenciada.

Para entendermos os diferentes posicionamentos assumidos pelos escravos, devemos assumi-los como fruto de uma combinação que reunia fatores objetivos e subjetivos. A defesa feita por Manuel do "Çacramento" e seus companheiros ganha sentido na medida em que podemos pensá-la condicionada pelas experiências dos envolvidos e pelas transformações que eles presenciavam na fazenda do Queimado e na cidade, a exemplos da crise agrícola, do advento do engenho central, do debate sobre a questão servil, da entrada dos imigrantes, da violência dos senhores, dos movimentos abolicionistas, das fugas e dos seus sentimentos de revoltas, entre outras.

Os escravos podem não ter lido o tal enunciado no periódico e tudo não passar de um grande acordo entre eles, contudo, o que nos interessa é essa história ter parecido factível, de modo que eles passaram a agir em função de um sentido diferente daquele

\footnotetext{
${ }^{87}$ Monitor Campista, n.104, p. 2, 13 mai. 1877. Hemeroteca periódicos, Arquivo Público Municipal Waldir Pinto de Carvalho, Campos dos Goytacazes, Rio de Janeiro.

88 Monitor Campista, n. 283, p. 2, 18 e 19 dez. 1876. Hemeroteca periódicos, Arquivo Público Municipal Waldir Pinto de Carvalho, Campos dos Goytacazes, Rio de Janeiro.
} 
sustentado pelos senhores. Assim, no relato do delegado e do escrivão, a posição assumida pelos escravos rebeldes em seus discursos foi a de sujeitos portadores de direitos, considerando-se que queriam receber jornal pelo seu trabalho ou ganhar a liberdade. Esse posicionamento dos cativos era um dos receios já alardeados pela classe senhorial em 1871. Ao especular sobre os efeitos da aprovação da Lei do Ventre Livre, como o aumento do número de escravos assumindo a posição de sujeito de direitos, o Barão da Parahyba e mais noventa fazendeiros assinaram uma representação que enviaram ao poder legislativo na qual, também, alertavam para a questão de que:

\begin{abstract}
A liberdade que vem da lei é muito diferente da liberdade que provêm do consentimento da generosidade; aquela desautoriza o domínio e abre a ideia do direito na alma do escravo, esta confirma a propriedade e robustece o domínio inspirando o reconhecimento do beneficiado tão eficaz para a manutenção da obediência. ${ }^{89}$
\end{abstract}

De fato, o barão considerou o aspecto mais sensível da lei, aquele que encorajava os escravos a rejeitarem a porta dos fundos do que era o costumeiro e a acreditarem que seria possível acessar a porta da frente dos direitos assegurados pela ordem legal. Assim, na luta por melhores condições de vida e trabalho, os cativos do Queimado se colocaram como sujeitos portadores de direitos, fossem pela lei ou pela "generosidade". Ora, esse juízo se demonstrou tanto pela negação do lugar que lhes era imposto naquela relação de exploração, quanto por eles se apropriarem de um enunciado sobre o trabalho livre e assumirem uma posição crítica e reflexiva diante da formação discursiva escravista. Por sua vez, tal formação justificava a "permanência" do cativeiro em nome dos interesses da nação, sendo essa pensada a partir dos interesses da classe senhorial.

\title{
Referências
}

BARONAS, Roberto Leiser (Org.). Análise do discurso: apontamentos para uma história da noção-conceito de formação discursiva. São Carlos: Pedro \& João Editores, 2007.

BARROS, Surya Aaronovich Pombo de (Org.) O estado da arte da pesquisa em história da educação da população negra no Brasil. Paraíba: SBHE/Virtual Livros, 2015.

Disponível em: <http://www.sbhe.org.br/e-books/sbhe-paraiba/sbhe-03 $\geq$. Acesso em: 15 jan. 2019.

BASTOS, Maria Helena Câmara. A educação dos escravos e libertos no Brasil: vestígios esparsos do domínio do ler, escrever e contar (Séculos XVI a XIX0. Cadernos de História da Educação, Uberlândia, v. 15, n. 2, p. 743-768, maio-ago. 2016

CARDOSO, Fernando Henrique. Capitalismo e escravidão no Brasil meridional: o negro na sociedade escravocrata do Rio Grande do Sul. São Paulo: Paz e Terra, 1977.

CARVALHO, José Murilo de. Pontos e bordados. Escritos de história e política. Belo Horizonte: Editora UFMG, 1998.

CASTRO, Hebe de Mattos Gomes de. Das cores do silêncio: os significados da liberdade no Sudeste escravista, Brasil século XIX. Rio de Janeiro: Nova Fronteira, 1998.

CHALHOUB, Sidney. Visões da liberdade: uma história das últimas décadas da escravidão na corte. São Paulo: Companhia das Letras, 1990.

CHARTIER, Roger. A leitura: uma prática cultural. In: CHARTIER, Roger (Org.). Práticas da leitura. São Paulo: Estação Liberdade. 2011.

CERTEAU, Michel de. A escrita da história. Rio de Janeiro: Forense Universitária, 1982.

89 Monitor Campista, n. 62, p.3, 06 jun. 1871. Hemeroteca periódicos, Arquivo Público Municipal Waldir Pinto de Carvalho, Campos dos Goytacazes, Rio de Janeiro. 
CONGRESSO Agrícola. Anais do Congresso Agrícola, realizado no Rio de Janeiro, em 1878. "Introdução" de José Murilo de Carvalho. Rio de Janeiro: Fundação Casa de Rui Barbosa, 1988. Edição fac-similar.

COSTA, Emília Viotti da. Da Senzala à colônia. São Paulo: Ed. Unesp, 1998.

FARIA, Sheila Siqueira Castro. Terra e trabalho em Campos dos Goytacazes, 1850-1920. 1985. Dissertação (Mestrado em História) - Programa de Pós-Graduação em História, Universidade Federal Fluminense, Niterói, 1985.

FONSECA, Marcus Vinícius. A arte de construir o invisível. O Negro na história da educação brasileira. Revista Brasileira de História da Educação, Maringá, v. 7, n. 1 (13), 2007, p.1150 .

Educação dos negros. Bragança Paulista: EDUSF, 2002.

FREYRE, Gilberto. Casa-grande \& senzala. São Paulo: Global, 2004.

GOMES, Ângela de Castro. Questão social e historiografia no Brasil do pós-1980: notas para um debate. Estudos Históricos, Rio de Janeiro, n. 34, p. 157-186, jul./ dez. 2004.

GORENDER, Jacob. O escravismo colonial. São Paulo: Ática, 1978.

GRANJEIRO, Cláudia Rejanne Pinheiro. Focault, Pêcheux e a formação discursiva. In: HAROCHE, Claudine; HENRY, Paul; PÊCHEUX, Michel. La sémantique et la coupure saussurienne: langue, langage, discours. Langages. Paris, n. 24, p. 93-106, 1971.

HOBSBAWM, Eric. A era dos impérios (1875-1914). Rio de Janeiro: Paz e Terra, 1988.

INDURSKY, Freda. Da interpelação à falha no ritual: a trajetória teórica da noção de formação discursiva. In: BARONAS, Roberto Leiser (Org.). Análise do discurso: apontamentos para uma história da noção-conceito de formação discursiva. São Carlos: Pedro \& João Editores, 2007.

KOSELLECK, R. Futuro passado: contribuição à semântica dos tempos históricos. Rio de Janeiro: Contraponto; PUC-Rio, 2006.

LARA, Sílvia Hunold. Campos da violência. São Paulo: Paz e Terra, 1988.

LEMOS, Carlos Eugênio Soares de. Vivendo em tempos de tirania. A Vila de São Salvador dos Campos dos Goytacazes: tão perto do Rio de Janeiro, tão longe do espírito Santo. Rio de Janeiro: Autografia, 2018.

LIMA, Lana Lage da Gama. Rebeldia Negra e abolicionismo. Rio de Janeiro: Achiamé, 1981.

LOPES, Katia Geni Cordeiro. Livres para aprender. Antes da abolição, escola-modelo criada por D. Pedro II abriu oportunidades para os ex-escravos. Revista de História da Biblioteca Nacional, Rio de Janeiro, n. 117, jun. 2015. p. 64-67.

MARQUESE, Rafael de Bivar. As desventuras de um conceito: capitalismo histórico e historiografia sobre a escravidão brasileira. Revista de História, São Paulo, n. 169, p. 223253, 2013.

MATTOS, Ilmar Rohloff de. O tempo Saquarema. São Paulo: Hucitec, 1987.

MATTOSO, Kátia de Queirós. Ser escravo no Brasil. São Paulo: Brasiliense, 1982.

OLIVEIRA, Cecília Helena L. de Salles. A astúcia liberal: relações de mercado e projetos políticos no Rio de Janeiro (1820-1824). Bragança Paulista: EDUSF; Ícone, 1999.

ORLANDI, Eni Pulcinelli. As formas do silêncio: No movimento dos sentidos. Campinas: Editora da Unicamp, 1995.

Análise de discurso: princípios e procedimentos. Campinas: Pontes.1999. 
PAIVA, Eduardo França. Leituras (im)possíveis: negros e mestiços leitores na América portuguesa. In: COLÓQUIO INTERNACIONAL POLÍTICA, NAÇÃO E EDIÇÃO, Belo Horizonte, 2003. Anais [...] Belo Horizonte: Programa de Pós-Graduação em História, Universidade Federal de Minas Gerais, 2003. v. 1.

PÊCHEUX, Michel. Semântica e discurso: uma crítica à afirmação do óbvio. Campinas, Editora da Unicamp, 1997.

O discurso: estrutura ou acontecimento. Campinas, SP: Pontes Editores, 2002.

PEREIRA, Walter Luiz Carneiro de Mattos. Francisco Ferreira Saturnino Braga: negócios e fortuna em Campos dos Goytacazes (séc. XIX). Revista História, São Paulo, v. 31, n. 2, 2012.

PIZARRO E ARAÚJO, José de Souza Azevedo. Memórias históricas do Rio de Janeiro. Rio de Janeiro: Impressão Régia, 1820-1822, tomo II. Rio de Janeiro: Ministério da Educação e Saúde; Instituto Nacional do Livro; Imprensa. Nacional, 1945-1946.

REIS, João José. A greve negra de 1857 na Bahia. Revista USP, São Paulo, n. 18, p. 6-29, 1993.

RIBEIRO, Rafaela Machado. O negro e seu mundo. Vida e trabalho no pós-Abolição em Campos dos Goytacazes (1883-1893). 2012. Dissertação (Mestrado em Sociologia Política) - Universidade Estadual do Norte Fluminense Darcy Ribeiro, Campos dos Goytacazes, 2012.

RIBEYROLLES, Charles. Brasil pitoresco: história, descrição, viagens, colonização, instituições. Belo Horizonte; São Paulo: Ed. Itatiaia; Ed. da Universidade de São Paulo, 1980.

SOARES, Márcio de Souza. A remissão do cativeiro. A dádiva da alforria e o governo dos escravos em Campos dos Goytacazes, 1750-1830. Rio de Janeiro: Apicuri, 2009.

TOMICH, Dale. Pelo prisma da escravidão. Trabalho, capital e economia mundial. São Paulo: Edusp, 2011. 